J. Lake Sci.(湖泊科学), 2019, 31(4): 988-997

DOI 10. 18307/2019. 0417

(C) 2019 by Journal of Lake Sciences

\title{
基于水生态改善的太湖分区分时动态水质目标制定方法
}

\author{
彭兆亮, 胡维平 \\ (中国科学院南京地理与湖泊研究所湖泊与环境国家重点实验室,南京 210008)
}

\begin{abstract}
摘 要: 科学、合理地制定水体主要污染物浓度控制目标,即水质目标是实施河、湖 “水质目标管理” 的基础和前提. 本文 基于环境条件决定生态系统结构以及自组织适应生态学原理, 提出一种可促进水生态改善的太湖分区分时动态水质目 标制定方法. 该方法在出人湖河道流量情景及分区污染物浓度情景设计的基础上, 进行不同情境下水生态系统要素时空 演化的数值试验; 然后以藻类生物量减小、沉水植物生物量增加为判据, 构造水质目标优化模型; 最后将湖泊水生态模型 与水质目标优化模型耦合, 判断各污染物浓度情景下水生态系统健康状况, 进而确定不同时间尺度下太湖各分区总氮、 总磷、氨氮、高锰酸盐指数等主要污染物指标的动态控制目标. 结果表明: 本方法制定的太湖各湖区分时水质目标相比传 统的“静态”目标更能促进太湖水生态系统健康发展, 并为太湖水环境的精细化管理提供了可能.
\end{abstract}

关键词: 太湖;水质目标;分区;分时段; 水生态改善

\section{A modelling approach for dynamic water quality target setting on multiple time-scales for subzones of Lake Taihu based on ecosystem improvement}

\section{PENG Zhaoliang \& HU Weiping}

( State Key Laboratory of Lake Science and Environment, Nanjing Institute of Geography and Limnology, Chinese Academy of Sciences, Nanjing 210008, P.R. China)

\begin{abstract}
Setting a scientific and reasonable water quality target is the basis for water quality target management for water bodies such as rivers and lakes. The purpose of this study is to develop a dynamic water quality target setting approach on multiple timescales for subzones of Lake Taihu in China. This approach is based on the ecological principles of self-organizing adaptation and that the ecosystem structure is decided by environment conditions. Monthly flow scenarios of main tributaries and pollutant concentration scenarios of each of the eight subzones of Lake Taihu were designed firstly. These scenarios were then fed into the EcoLake model to simulate the evolution of water ecosystem variables. A water quality target optimization model was set up to identify the best pollutant concentration scenarios. The optimization model uses algal biomass and submerged plant biomass as optimization metrics. The optimization model was integrated to the EcoLake model lastly to determine the best control targets of total nitrogen, total phosphorus, ammonia nitrogen and permanganate index. The results suggest that the water quality target set in this study is more advanced in terms of promoting water ecosystem condition and supporting fine water environment management for Lake Taihu, comparing to traditional water quality target.
\end{abstract}

Keywords: Lake Taihu; water quality target; subzones; multiple time-scales; ecosystem improvement

湖泊富营养化及与之相伴的藻类异常增殖与藻类水华已成为全球性的水环境问题之一 ${ }^{[1-2]}$. 我国湖泊 众多, 自 1980s 以来, 我国经济社会经历长期高速发展, 人湖污染物总量不断增加, 并不断在湖泊内累积, 导 致大量浅水湖泊生态系统出现显著退化, 水体富营养化严重, 自净能力下降, 水质发生了严重恶化的现象. 2009 年湖泊调查数据显示, 太湖等长江中下游浅水湖泊在丰水期和枯水期有 $70 \%$ 以上处于富营养水平 ${ }^{[3]}$, 且藻类水华频发,严重损害了湖泊的生态服务功能及供水安全,引起了各级政府的高度重视.

* 国家自然科学基金项目 (41701567)、江苏省自然科学基金项目 (BK20151064) 和中国科学院重点部署项目 (KZZDEW-10-01) 联合资助. 2018-10-29 收稿; 2018-12-28 收修改稿. 彭兆亮 (1985 ), 男, 助理研究员, 博士; E-mail: zlpeng@ niglas.ac.cn. 
国内外水污染治理的研究和实践经验证实,将污染物排放量控制在河、湖、海洋等水体功能发挥所允许 的范围之内, 即实施 “水质目标管理” 是水体水环境治理的关键 ${ }^{[4]}$. 目前, 发达国家水环境管理普遍以贯彻 “水质目标管理” 为前提. 如欧盟的《水框架指令》 ${ }^{[5]}$ 和《海洋战略框架指令》 ${ }^{[6]}$, 美国环境保护署的《清洁水 法案》 ${ }^{[7]}$, 澳大利亚的《水质提升计划》 ${ }^{[8]}$ 等都明确了未来不同时期河、湖等内陆水体及海湾的保护目标来指 导水环境管理.

实施 “水质目标管理” 的前提是科学、合理地确定水体主要污染物浓度控制目标, 即水质目标. 在目前制 定的太湖水功能区水质目标中, 整个太湖仅被设为两种目标水质: 一种为 III 类, 主要包括竺山湖保护区、梅 梁湖无锡饮用水水源和景观娱乐用水区、贡湖饮用水水源保护区、胥湖苏州饮用水水源和景观娱乐用水区. 第二种为 II 类或 III 类,包括太湖湖体保护区 (东太湖、湖心区、西部沿岸区) 、苏浙边界缓冲区. 太湖为大型 浅水湖泊,水文水动力过程以及生态系统结构存在巨大的空间差异, 藻类水华的暴发不仅仅与暴发水域的 水质有关, 还与风向、风速、上风方向生态系统结构、水文条件等密切相关. 依太湖水体自北向南、自西向东 流动的水文特征和水生植被广泛分布于贡湖东南部、湖东滨岸区及东太湖的特点, 相对湖东滨岸区、贡湖而 言, 湖西区、竺山湖、湖心区目标水质定得过严, 使得这些水域的水质目标难以实现, 不利于上游地区的污染 减排; 相反, 湖东滨岸区、贡湖目标水质定得过松, 意味着苏州市等可以向太湖大量排污, 很难起到促进污染 减排的作用.

此外, 在水功能区水质目标确定方面对水体的使用功能关注较多, 而对水体自然属性、生态系统结构以 及服务功能对水质及使用功能的影响关注较少. 在太湖等草一藻型生态系统并存湖泊, 污染物氮、磷浓度降 低到一定程度时会导致湖泊生态系统由藻型向草型转换, 水草分布面积增加, 藻类生长将受显著抑制, 水华 消失, 从而能确保水体使用功能的正常发挥, 促进湖泊生态系统的可持续发展; 反之, 氮、磷等营养盐浓度升 高到一定程度时, 湖泊生态系统由草型向藻型转化, 藻类水华发生频率和规模增大, 损害水体使用功能. 由 此可见, 制定太湖氮、磷等物质浓度目标仅考虑水体使用功能显然不够, 必须考虑湖泊生态系统结构的稳定 性与演变. 在当前特别需要将水体氮、磷控制的目标浓度与藻类水华发生频率、规模以及水生植被的保护结 合起来.

本文针对太湖目前水质目标制定过程中存在的上述问题, 基于环境条件决定生态系统结构和演变, 生 态系统对环境的可产生反馈作用以及自组织适应生态学原理,提出一种基于水生态改善的太湖分区分时动 态水质目标制定方法, 为太湖水环境的精细化管理, 保障供水安全及促进水生态可持续发展提供支撑.

\section{1 数据与方法}

\section{1 数据收集}

以 2013 年为例说明太湖分区分时动态水质目标制定方法. 2010-2013 年主要出人湖河道逐日流量数 据、逐月水质巡测数据来源于水利部太湖流域管理局. 水质数据包括 32 个水质监测点位 (本文研究区涉及 其中的 30 个点位数据, 图 1A), 以及总氮、总磷、氨氮、高锰酸盐指数等 12 项常规监测指标. 1956-2013 年 逐日气温、降水量、风速风向长系列数据来源于中国气象数据共享网. 逐时风速风向、太阳辐射等气象要素 监测数据来源于国家气象站东山基本站以及自设的微型气象站.

依据水质监测数据使用动态聚类方法将太湖划分为 8 个湖区, 分别为梅梁湖、贡湖、竺山湖、湖西区、湖 南区、东太湖、湖东区及湖心区. 值得注意的是, 本文湖区依据太湖水质空间分布特征划分, 与太湖流域管理 局划分的湖区数量一致,但具体湖区范围存在一定的差异. 从图 1B 可以看出, 不同湖区污染物浓度存在明 显的时空差异. 2011-2013 年间竺山湖总体污染物浓度最高, 且年际波动幅度较大, 湖西区、湖南区次之; 东 太湖和湖东区相对较低, 水质较好.

\section{2 太湖分区分时动态水质目标制定计算流程}

太湖分区分时段水质目标制定以三维水动力生态模型为基础, 在模型参数率定与验证的基础上,建立 水质目标优化模型, 用以制定未来不同月份、季度及全年 3 个不同时段,太湖 8 个湖区总氮、总磷、氨氮及高 锰酸盐指数 4 项主要水质指标动态控制目标. “动态” 是指在各月月初利用最新观测数据开展数值模拟, 进 而对水质目标进行优化调整. 以 2013 年 7 月初制定 7 月水质目标为例, 具体说明分区分时水质目标制定方 
法及流程, 其他月份及季、年尺度的水质目标制定过程类似.

步骤 1: 出人湖河道概划、河道流量与分区水质情景设计.

太湖位于平原河网区, 河道纵横, 出人太湖河道口门超过 200 个. 依据流量监测情况, 将其概划为 64 条 主要河道. 对河道流量数据进行频率分析, 确定 7 月不同保证率对应的典型年及相应河道流量. 根据分区水 质监测数据, 进行分区水质情景设计.
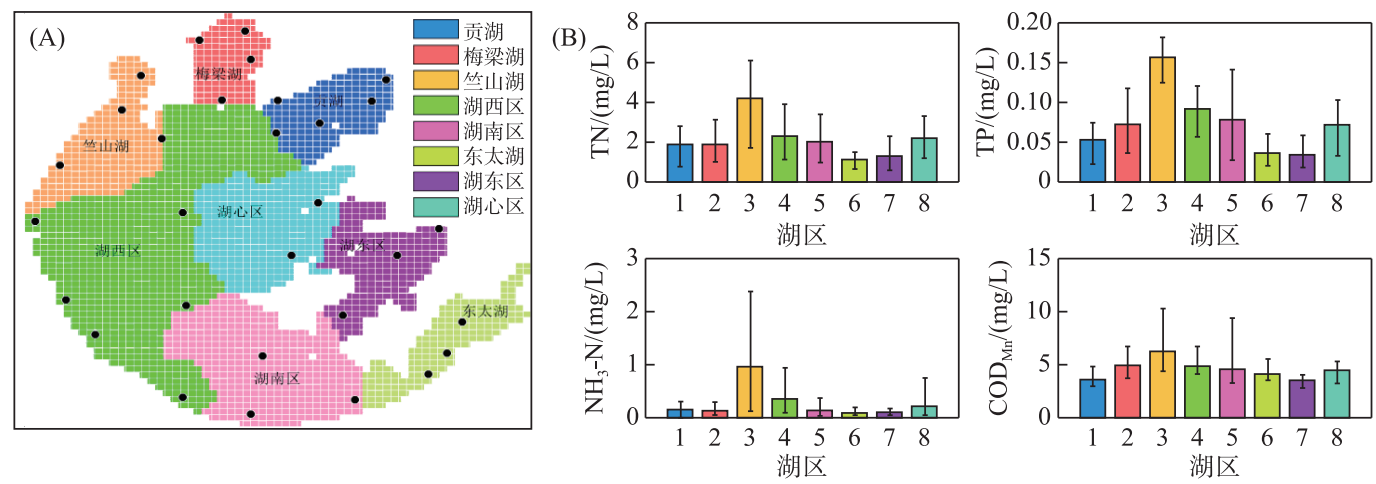

图 1 太湖湖区划分 (A, 图中黑点代表 30 个水质巡测点位位置);

各区 2010-2013 年总氮、总磷、氨氮和高锰酸盐指数变化情况 (B)

Fig.1 Subzones of Lake Taihu, the black dots show the 30 sampling sites (A); Annual mean values of total nitrogen, total phosphorus, ammonia nitrogen and permanganate index concentrations of subzones during 2010-2013 (B)

步骤 $2:$ 初值场与外部函数预处理.

根据 2013 年 7 月初的太湖水质监测数据, 利用反距离加权平均的方法生成模型计算污染物浓度初值 场. 根据步骤 1 确定的 7 月份不同保证率对应的典型年份 (如典型丰水年为 1998 年), 进行 1998 年 7 月降 水、蒸发、气温、太阳辐射以及各主要出人湖河道流量情景、8 个分区总氮、总磷、氨氮、高锰酸盐指数等水质 情景的时空插值等预处理, 处理成模型所需格式.

步骤 $3:$ 太湖分区水生态系统时空演化数值试验.

进行不同流量情景及不同分区水质情景以及外部函数驱动下 2013 年 7 月太湖水动力及藻类、沉水植 物、浮游动物、鱼类等水生态要素时空演化的数值模拟, 并保存计算结果. 重复此步骤, 直至所有水文情景、 水质情景下水生态演化过程模拟结束.

步骤 4 :分区分时水生态健康评估与水质目标优选.

建立以分区藻类生物量及沉水植物生物量为指标的分区水质目标优选模型; 对不同水文情景及水质情 景下太湖分区水生态健康演化趋势进行评估, 优选出不同水文情景下各分区目标水质浓度; 为分区目标水 质下的水环境容量计算与环境容量河道人湖断面分配等水质目标精细化管理提供依据.

\section{3 分区水质情景设计}

目前太湖流域管理局、中国科学院南京地理与湖泊研究所等管理、科研单位已实现太湖全湖常态化的 逐月水质巡测, 积累了大量水质数据. 因此, 分区水质情景设计考虑根据最近 3 年的水质监测结果, 首先计 算各个水质监测点位各月总氮、总磷、氨氮、高锰酸盐指数等近 3 年平均值, 再将该平均浓度值按反距离加 权平均的方法插值到太湖所有计算单元中, 计算 8 个分区不同污染物各月平均浓度. 在此基础上, 各分区水 质指标浓度按 $1 \%$ 的比例依次减少到 $50 \%$ 或增加到 $10 \%$, 得到各分区各月水质浓度情景. 保持某一浓度值不 变的前提下将其输人到模型中, 进行太湖各分区藻类等水生态系统的数值模拟, 计算藻类生物量、沉水植物 生物量等水生态系统指标在不同营养盐浓度下的时空演化趋势.

\section{4 不同水文和水质情景下太湖水生态系统演化数值模拟}

不同水文和水质情景下太湖水生态系统演化数值模拟选用三维水动力生态模型—EcoLake. 该模型 


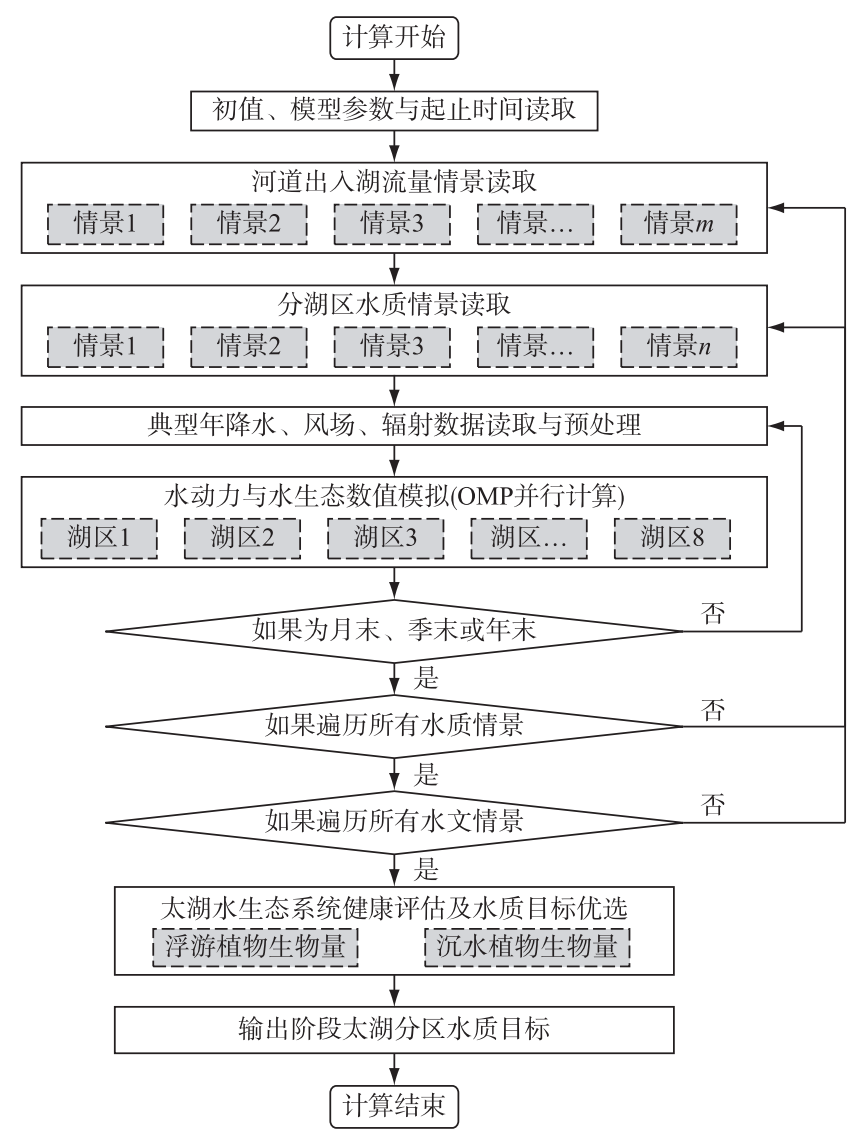

图 2 太湖分区分时动态水质目标制定流程

Fig. 2 Flowcharts of the water targets setting on multiple time-scales for subzones of Lake Taihu

由 EcoTaihu 模型发展而来 ${ }^{[9-12]}$, 可同步模拟和预测浅水湖泊三维湖流、营养盐转化输移、藻类、浮游动物、水 生植物及鱼类时空演化特征. EcoLake 与其他模型显著区别在于不但包括了氮、磷等决定水质类别指标, 也 包含了决定湖泊生态系统类型的藻类和沉水植物, 还明确地指明了各类物质转化的趋向, 可计算太湖每年 氮、磷等在水相、沉积物相以及生物相的储存量以及转化量. EcoLake 目前已被成功地应用于 “引江济太”改 善太湖水质效果评估 ${ }^{[13]}$ 、太湖流域水资源保护局太湖藻类水华预警预测 ${ }^{[14]}$ 、湖泊水体自净能力的估算 ${ }^{[15]}$ 、 阳澄湖生态系统优化提升阳澄湖生态系统优化提升情景预测 ${ }^{[16]}$ 等众多科研课题及工程实践中. 经多年资 料验证, 该模型可较好地反映浅水湖泊水质, 澡类及水生植物的时空变化特征 ${ }^{[13]}$.

EcoLake 模型主要由三大模块组成,第一块为相对独立的水动力学湖流、水位变化模块; 第二块为食物 链网模块,包括鱼类、有机碎屑、浮游动物、藻类以及高等水生植物; 第三块为物质输移转化模块,包括溶解 氧输移转化子模块、氮输移转化子模块和磷输移转化子模块. 因藻类和沉水植物为太湖两类最为重要的水 生态系统要素, 也是本方法重点关注的水生态要素, 在此仅介绍 EcoLake 模型中藻类和沉水植物生长的控制 方程.

对于湖泊藻类而言, 光合作用是主要的能量来源, 营养盐是合成有机物质的基础, 温度是影响生长的关 键因子. 除此之外, 湖流、波浪、水生植物、浮游动物、鱼类等对藻类的生长也存在影响. 就湖泊中的一个水体 单元而言, 影响藻类生物量变化过程除图中影响藻类生长和死亡要素外, 就是单元水体中藻类与周边水体 交换,模型在假设藻类颗粒为连续分布悬浮物前提下采用悬浮物对流扩散方程表示藻类生物量控制方程: 


$$
\frac{\partial B P}{\partial t}+u \frac{\partial B P}{\partial x}+v \frac{\partial B P}{\partial y}+\left(w+\frac{F-w_{\mathrm{BP}}}{H}\right) \frac{\partial B P}{\partial \sigma}=E_{\mathrm{h}}\left(\frac{\partial^{2} B P}{\partial x^{2}}+\frac{\partial^{2} B P}{\partial y^{2}}\right)+\frac{\partial}{H \partial \sigma}\left(E_{\mathrm{Z}} \frac{\partial D O}{H \partial \sigma}\right)+\varepsilon(B P)+B P_{\mathrm{g}}-B P_{\mathrm{M}}
$$

式中, $u 、 v 、 w$ 分别为笛卡尔坐标系下湖流正东、正北、铅直向上流速分量; $B P$ 为藻类生物量; $w_{\mathrm{BP}}$ 为藻类在太 阳辐射为零时垂直运动的速度; $H$ 为水深 $; F$ 为太阳辐射为非零时藻类上浮的速度 $; B P$ g 为藻类利用太阳辐射 光合作用生长量; $B P_{\mathrm{M}}$ 为藻类正常的死亡量 $; E_{\mathrm{h}}$ 为藻类水平湍流扩散系数; $E_{\mathrm{z}}$ 为藻类垂直扩散系数; $\varepsilon(B P)$ 为方程因坐标变化水平扩散项产生的偏差项.

因沉水植物通过其根固着于湖底, 沉水植物不随水体运动, 因此, 沉水植物生长控制方程可表示为:

$$
\frac{\partial S B}{\partial t}=E_{\mathrm{SB}}\left(\frac{\partial^{2} S B}{\partial x^{2}}+\frac{\partial^{2} S B}{\partial y^{2}}\right)+G S B_{\max } \cdot f_{S}(T) \cdot f_{S}(N, P) \cdot f_{S}(I) \cdot S B(1-S B / C S)
$$

式中, $S B$ 为沉水植物密度 $\left(\mathrm{kg} / \mathrm{m}^{2}\right), E_{\mathrm{SB}}$ 沉水植物扩张系数, $G S B_{\text {max }}$ 沉水植物内京增长率, $f_{S}(T) 、 f_{S}(N, P)$ 、 $f_{S}(I)$ 分别代表气温、氮磷营养盐以及光照条件对沉水植物生长的影响.

采用正交网格对太湖计算单元进行空间划分, 网格东西向步长、南北向步长为 $1 \mathrm{~km}$ (图 $1 \mathrm{~B})$, 垂向分为 5 层.

\section{5 水生态系统健康状况评估与水质目标优选}

目前湖泊水生态系统健康状况评估存在诸多的方法与评价指标体系. 湖泊生态系统健康, 不但表现在 能够提供特殊功能的能力 (如调蓄洪水、净化水质、保持水生生物多样性等), 而且具有维持自身有机组织的 能力. 当输人的营养盐过多时, 湖泊将发生富营养化, 在以藻类为生物建群种的水体中, 在合适的水文气象 条件下, 易暴发藻类水华; 水生植物, 特别是沉水植物为 “浅水湖泊稳态转换理论” 关注的重要对象. 在以沉 水植物为生物建群种的水体中, 因沉水植物生长对水体营养盐吸收、遮光、以及提供其他生物生境及保护等 机制, 藻类生长受到抑制, 存量较低, 加之沉水植物固着底泥沉积物与抑制风浪作用下底泥沉积物的再悬 浮, 水体透明度高, 生态系统净化污染物能力强, 水体能够维持良好水质. 太湖的主要生态环境问题为水体 富营养化与藻类水华问题突出. 因此, 本着科学性、简明性及可操作性的原则, 选取藻类生物量与沉水植物 生物量为评价指标, 建立分区分时水质目标优选模型, 用以评估各湖区不同时段总氮、总磷、氨氮、高锰酸盐 指数保持在不同浓度情景下的水生态系统健康状况, 最终优选出最适宜的污染物目标浓度. 水质目标优选 模型以水生态系统健康指数最大值为优选目标:

$$
W E I=\max \sum_{n=1}^{N}\left(-B A_{n} \cdot w_{1}+B S_{n} \cdot w_{2}\right)
$$

式中, $W E I$ 为水生态系统健康指数; $n=1,2, \cdots, N$ 为各水质情景; $B A_{n} 、 B S_{n}$ 分别为第 $n$ 种水质浓度情景下 的藻类、沉水植物生物量, 以藻类生物量减少、沉水植物生物量增加为目标; $w_{1} 、 w_{2}$ 分别为 2 种评价指标的 权重. 由于 2 种指标对于指示太湖水生态系统健康水平都具有重要的作用, 因此将每种指标赋予相同的权 重, 即 $w_{1}=w_{2}=0.5$.

在制定水质情景时, 考虑到在实际的水质目标管理过程中, 湖泊污染物浓度值不可能会被无限制的削 减, 根据目前太湖的水质状况, 考虑以 $50 \%$ 为最大削减量, 以 $10 \%$ 为最大允许增加量为限值条件来优选水质 目标.

\section{2 结果分析}

\section{1 不同水质情景下太湖各湖区水生态系统要素变化}

2.1 .1 藻类生物量变化 太湖不同湖区生态系统结构存在明显差异,因此在不同水质情景下, 分湖区不同时 期藻类生物量对水质变化的响应也存在明显的差异. 图 3 显示了在平水年条件下,太湖分湖区 2013 年在 2010－2012 年均值基础上,湖体各水质指标浓度在各月保持在下降 5\%、10\%、15\%、20\%、30\%、40\%、50\% 及 上升 5\%、10\% 等 9 种水质情景下, 贡湖等 8 个湖区 1-12 月藻类生物量相比过去 3 年同期数值的相对变化 百分率, 其中纵坐标代表各水质情景, 横坐标代表月份, 方块颜色代表平均藻类生物量相比过去 3 年的变化 情况. 可以看出, 在年初的 $1-3$ 月, 各湖区藻类生物量对水质变化不是十分敏感, 只有湖西区和竺山湖随着 污染物浓度的下降藻类生物量出现略微的上升. 在藻类开始萌发至快速繁殖的 4-10月, 各湖区藻类生物 
量基本呈现出随着污染物浓度上升而上升, 污染物浓度下降而下降的趋势. 但不同湖区在各月的变化幅度 具有明显的时空差异. 比如贡湖只有在 4-5 月和 10 月藻类生物量对水质变化最为敏感,在其他月份只随 着污染物浓度的大幅变化出现轻微的响应. 湖西区、湖南湖及湖心区各月藻类生物量对污染物浓度变化最 为敏感, 基本与污染物浓度同步上升或下降. 在水质较好、藻类生物量较低的东太湖、湖东区湖区, 藻类生物 量只在 10 月或 12 月呈现出明显的与污染物浓度同步变化的趋势, 其他月份变化幅度要小得多. 由于篇幅 限制, 本文只分析平水年条件下分湖区分时藻类、沉水植物生物量在不同水质情景下的相对变化, 目标函数 值及具体分区分时水质目标.

(a) 贡湖

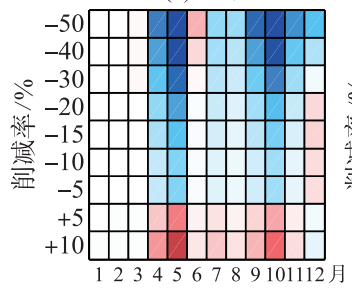

(e) 湖南区

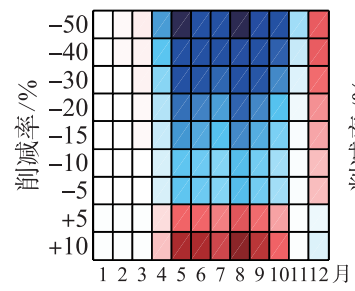

(b) 梅梁湖

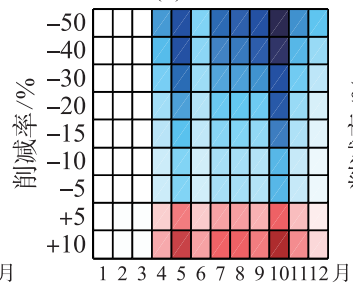

(f) 东太湖

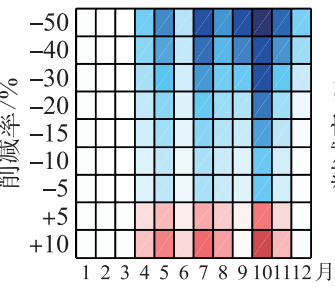

(c) 䇥山湖

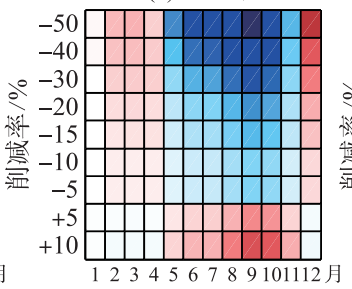

(g) 湖东区

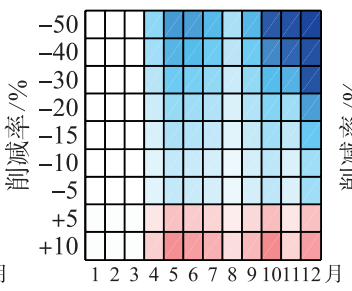

(d) 湖西区

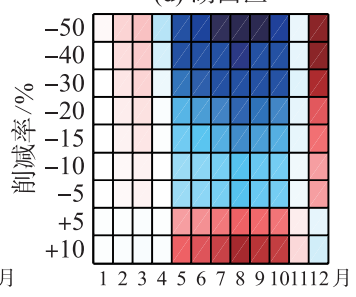

(h) 湖心区

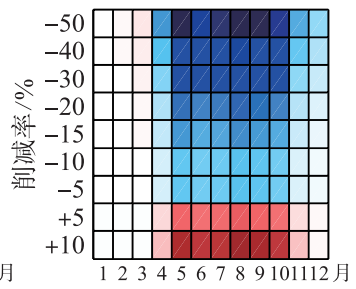

藻类生物量变化率 $/ \%$

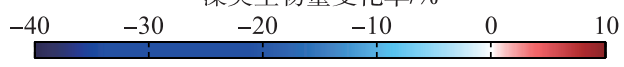

图 3 不同水质情景下各湖区藻类生物量变化率

Fig.3 Algal biomass variation of each subzone under different water quality scenarios

2.1.2 沉水植物生物量变化 图 4 为太湖 2013 年在年初水质监测值基础上,湖体各水质指标浓度在各月保 持在下降 5\%、10\%、15\%、20\%、30\%、40\%、50\% 及上升 5\%、10\%等 9 种水质情景下, 贡湖等 8 个湖区 $1-12$ 月沉水植物生物量相比保持在年初水质基准上变化的百分率. 梅梁湖、竺山湖、湖西区及湖南区沉水植物分 布较少, 其生物量对水质变化响应不明显. 尽管其他湖区有不同密度的沉水植物分布, 但在当前太湖总体长 期呈富营养化的状态下, 沉水植物生物量对水质变化的响应不敏感, 各月生物量变化波动为 $\pm 0.5 \%$, 其中贡 湖沉水植物生物量对于水质变化相对最为敏感. 总体而言, 贡湖、东太湖、湖东区、湖心区沉水植物生物量变 化趋势与污染物浓度呈正比, 即当湖区污染物浓度变高时,沉水植物生物量呈轻微增长的趋势.

\section{2 不同水质情景下目标函数值}

图 5 给出了不同水质情景下太湖各湖区逐月水生态系统评估模型目标函数值. 不同湖区不同月份在各 水质情景下的水生态系统目标函数值存在较大的时空差异, 但总体呈现出目标函数值随削减比例的增大而 增高的趋势, 即水生态健康随水质的好转而好转. 比如贡湖, 在 4-5 和 9-10月目标函数值随着污染物浓 度的降低呈明显增高的趋势, 其他月份增加的幅度相比上述 4 个月份不是十分明显. 对于湖西区、湖南区和 湖心区, 在 5-10月目标函数值都呈现随污染物浓度降低而逐渐增高的趋势, 在其他几个月都呈轻微降低 的趋势. 由此可见, 在当前的评估体系下, 并非水质目标定的越低越有利于各湖区生态系统朝健康的趋势发 展. 相比其他月份, 各湖区目标函数值在 $1-3$ 月的变化相对较小.

\section{3 各湖区不同时段水质目标}

2.3.1 总氮目标浓度 从图 6 中可以看出, 不同湖区总氮目标存在明显时空差异, 这是由太湖总氮浓度时空 
(a) 贡湖

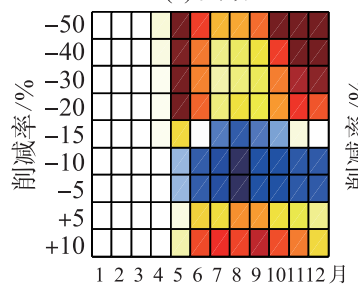

123456789101112 月 (b) 东太湖

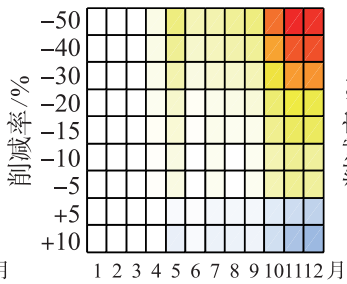

(c) 湖东区

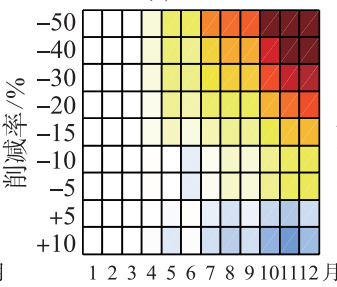

(d) 湖心区

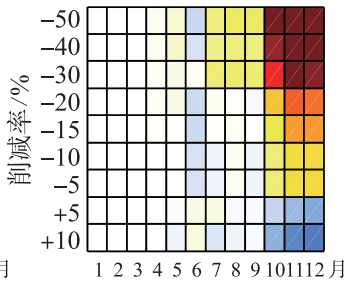

沉水植物生物量变化率 $\%$

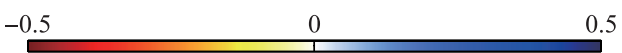

图 4 不同水质情景下各湖区沉水植物生物量变化率

Fig.4 Submerged plant biomass variation of each subzone under different water quality scenarios

(a) 贡湖

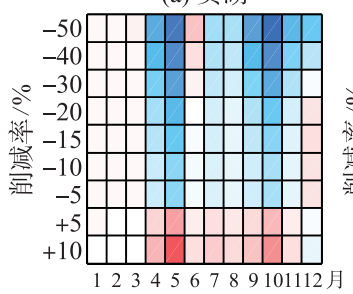

(e) 湖南区

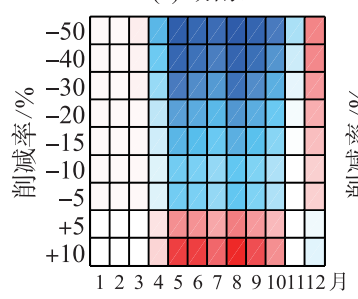

(b) 梅梁湖

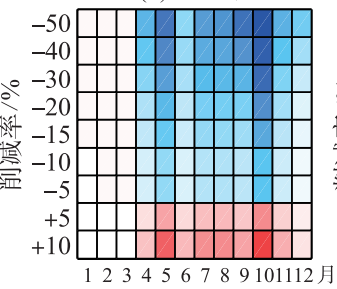

(f) 东太湖

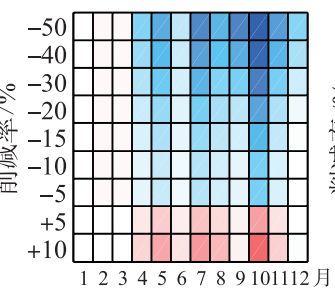

(c) 竺山湖

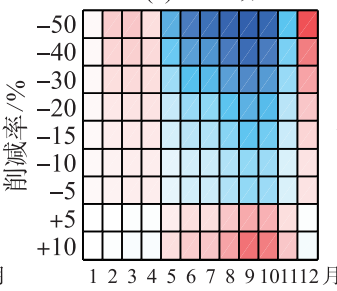

(g) 湖东区

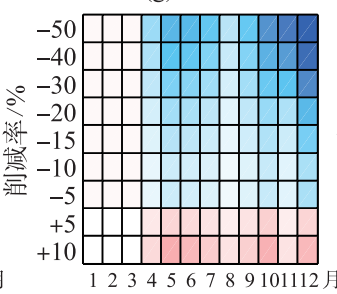

(d) 湖西区

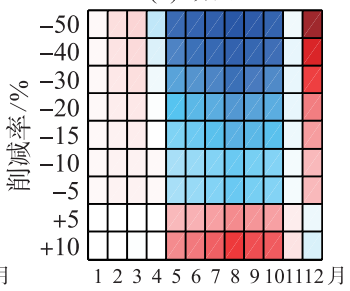

(h) 湖心区

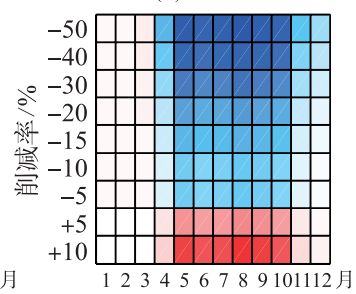

目标函数值 $/ \%$

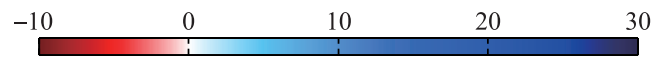

图 5 不同水质情景下各湖区生态系统评估目标函数值

Fig.5 Objective function values of the lake ecosystem evaluation model of each subzone under different water quality scenarios

分布与净化能力差异决定的. 从季节分布上来看, 总氮目标冬春季节相对较高、夏秋季节相对较低. 如贡湖 总氮目标在 $1-3$ 月和 12 月均在 $2 \mathrm{mg} / \mathrm{L}$ 以上, $9-11$ 月均在 $1 \mathrm{mg} / \mathrm{L}$ 以下. 从空间上来看, 竺山湖总氮目标 浓度最高, 1 月的目标浓度达到 $5.09 \mathrm{mg} / \mathrm{L}$. 东太湖、湖东区目标浓度相对最低, 1 月的目标浓度分别为 1.22 和 $1.0 \mathrm{mg} / \mathrm{L}$, 达到 $\mathrm{IV}$ 类标准.

2.3.2 总磷目标浓度 图 7 显示了太湖 2013 年 8 个分区各月总磷控制目标浓度. 各分区总磷目标浓度存在 明显的时空差异. 从时间上来看, 总磷控制目标浓度冬春季节高、夏秋季节低, 12 月至 3 月贡湖总磷的目标 浓度在 $0.05 \mathrm{mg} / \mathrm{L}$ 以上, 为 $\mathrm{I}$ 类标准; 7-9 月为 $0.02 \mathrm{mg} / \mathrm{L}$, 达到 II 类标准. 从空间上来看, 竺山湖总磷目标 浓度最高, 东太湖、东部沿岸区最低. 1 月竺山湖总磷控制目标为 $0.18 \mathrm{mg} / \mathrm{L}$, 为 $\mathrm{V}$ 类标准, 而东太湖、东部沿 岸区则分别为 0.05 和 $0.06 \mathrm{mg} / \mathrm{L} ; 2$ 月竺山湖总磷目标浓度为 $0.14 \mathrm{mg} / \mathrm{L}$, 东太湖、湖东区为 $0.04 \mathrm{mg} / \mathrm{L}$, 达到 III类标准. 由于篇幅限制,在此只分析总氮和总磷浓度目标. 

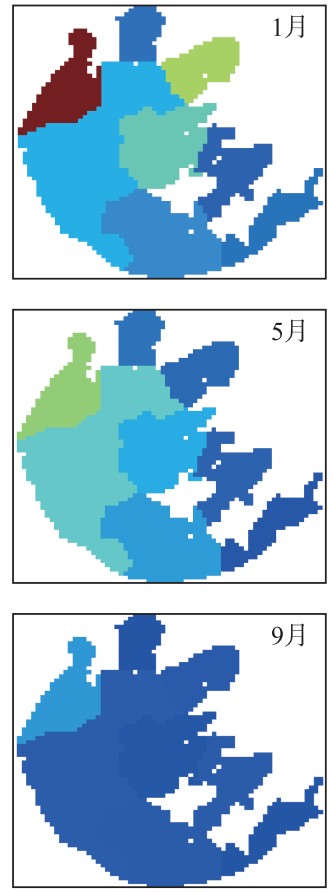

图 6 太湖 2013 年各分区各月总氮浓度控制目标

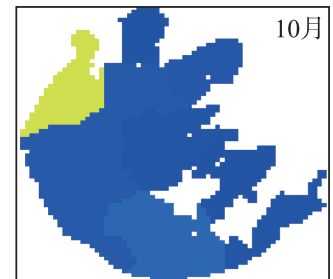

0

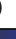
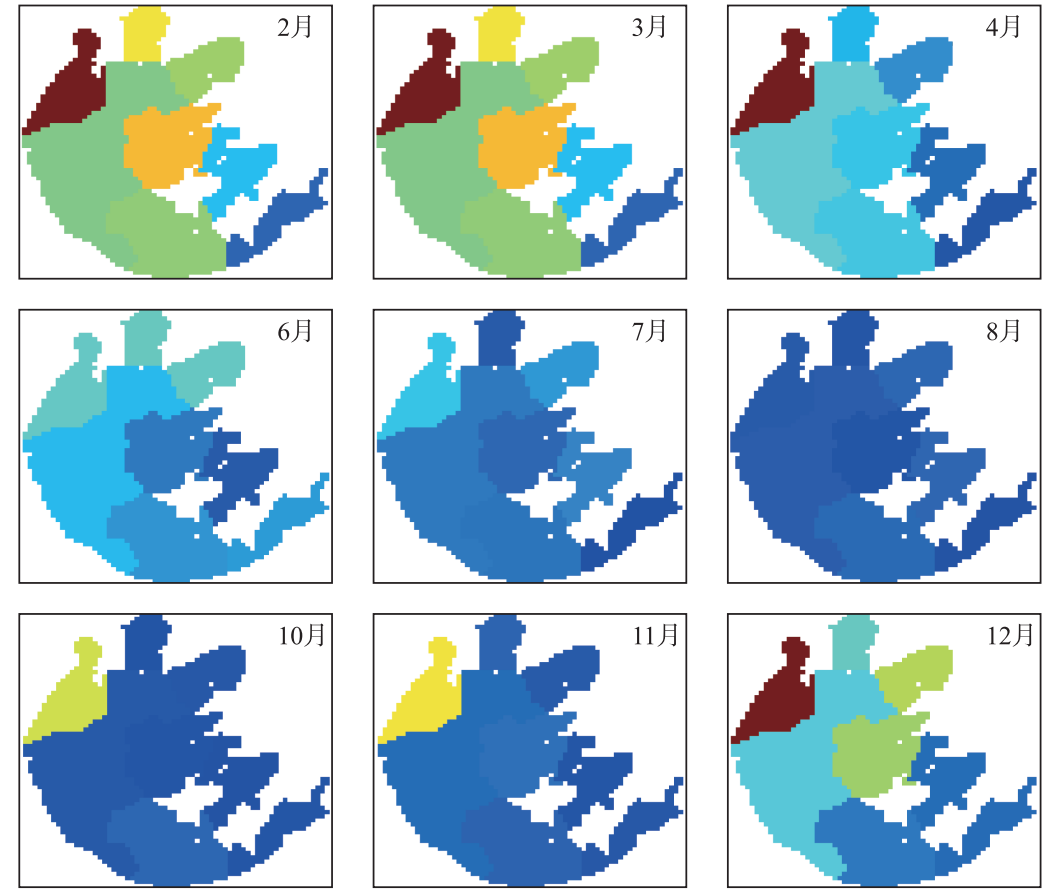

$\mathrm{TN} /(\mathrm{mg} / \mathrm{L})$

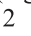

2

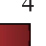

Fig.6 Monthly total nitrogen concentration targets for each subzone of Lake Taihu in 2013

\section{3 讨论}

2013 年 12 月出台的《太湖流域水环境综合治理总体方案 ( 2013 年修编)》提出了太湖流域河 湖水环 境治理的总体目标和治理方向. 要求着力改善环湖生态环境, 力争到 2020 年, 使污染物排放量得到大幅削 减, 水环境质量得到较大改善, 努力修复湖泊生态系统, 提高湖泊健康水平, 实现流域经济社会和环境协调 发展. 同时提出了按照总量控制、分项管理的原则对 COD、氨氮、总磷、总氮等关键性指标按分期、分级、分类 确定控制目标, 要求到 2015 年全湖总氮浓度由 2010 年的 $2.68 \mathrm{mg} / \mathrm{L}$ 下降到 $2.2 \mathrm{mg} / \mathrm{L}$; 总磷浓度由 2010 年的 $0.073 \mathrm{mg} / \mathrm{L}$ 下降到 $0.06 \mathrm{mg} / \mathrm{L}$; 高锰酸盐指数稳定保持在 III类、氨氮稳定保持在 II 类, 并进一步改善. 太湖流 域管理局发布的《2013 太湖健康状况报告》表明 2013 年太湖全年的总氮浓度已经下降到 $1.97 \mathrm{mg} / \mathrm{L}$, 达到 V 类标准; 全湖氨氮浓度下降到 $0.15 \mathrm{mg} / \mathrm{L}$, 达到 I 类标准, 高锰酸盐指数相比 2010 年有所升高, 为 $4.83 \mathrm{mg} / \mathrm{L}$. 2013 年实测总氮、氨氮、高锰酸盐指数浓度已经低于《总体方案修编》2015 年目标值(图 8). 相比《总体方案 修编》提出的静态水质目标, 本文提出的动态水质目标方法可以根据太湖水质以及水生态系统实时状态, 对 太湖水质目标作出及时动态调整, 因此制定的水质目标具有更好的灵活性和可操作性. 此外, 可根据管理上 需要, 制定月、季、年 3 种不同尺度的水质目标, 并考虑到太湖不同湖区生态系统结构差异, “因地制宜”地确 定不同湖区合理的污染物控制浓度, 对于促进太湖生态环境的精细化管理, 以及藻类水华控制和水生态逐 步改善等方面都具有一定的积极意义.

由于目前尚未建立起系统的、完整的浮游动物、鱼类、底栖动物等太湖水生态系统其他重要要素观测机 制, 本文建立的太湖水生态系统健康评估及水质目标优选模型只考虑了藻类生物量和沉水植物生物量两项重 要指标, 尚不能全面、完整地反映太湖水生态系统健康状况, 因此模型对于准确把握太湖水生态系统健康状况 的演化趋势进而制定更加合理的水质目标方面存在一定的局限性. 随着我国对太湖生态环境治理力度的进一 

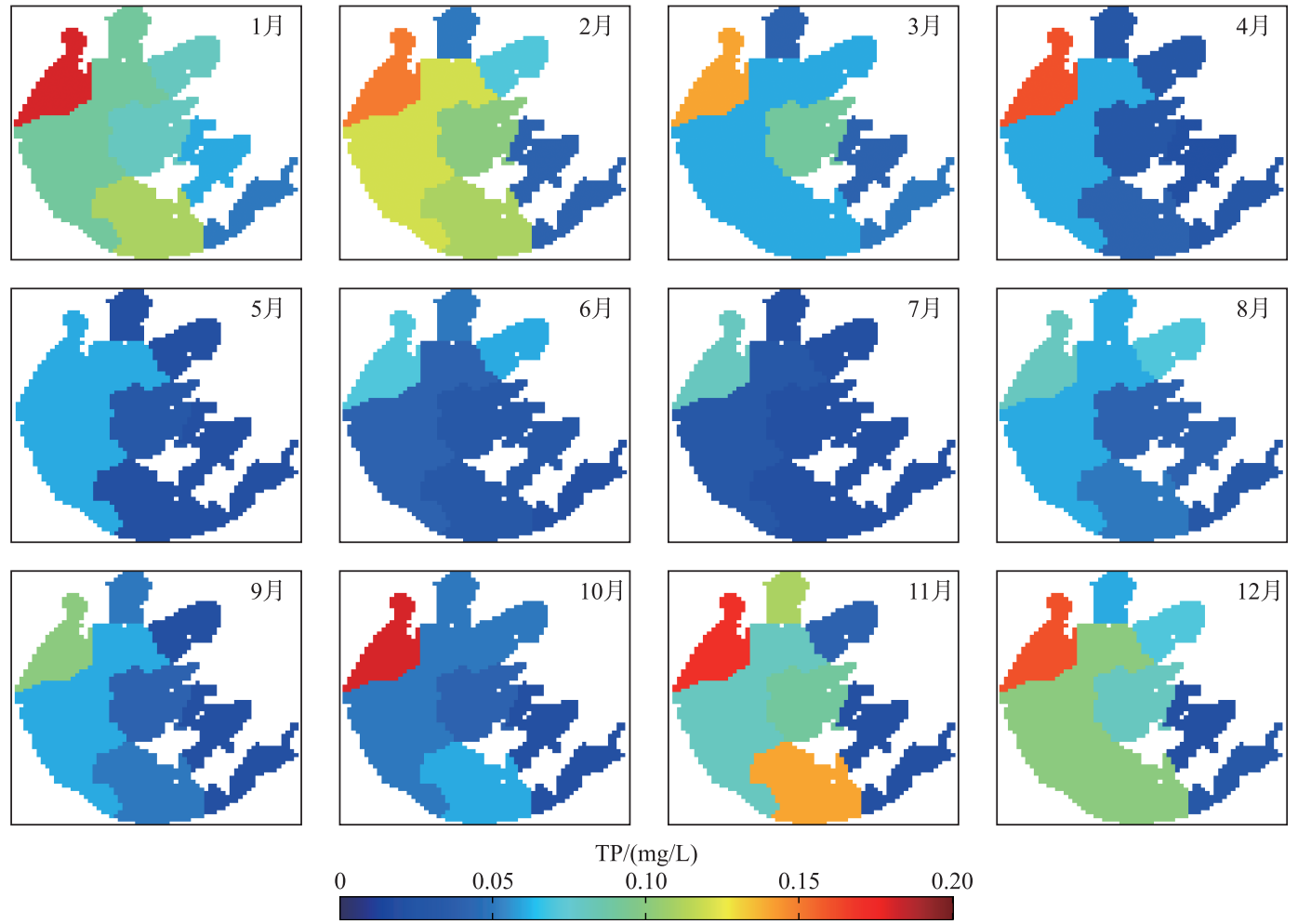

图 7 太湖 2013 年各分区各月总磷浓度控制目标

Fig.7 Monthly total phosphorus concentration targets for each subzone of Lake Taihu in 2013
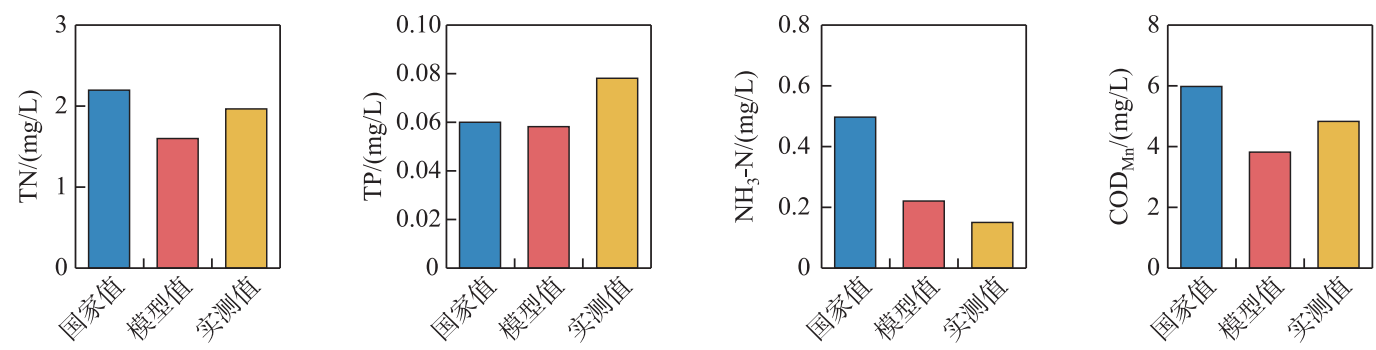

图 82013 年太湖全湖国家水质目标、模型模拟水质目标与实测值对比

Fig. 8 Comparison of different water quality targets for Lake Taihu with corresponding observations in 2013

步加强, 观测网络和观测机制的逐步完善, 以及观测数据的累积, 在今后的研究及太湖水环境精细化管理中, 可以考虑增加水生态系统健康评估指标, 进一步完善太湖水生态健康评估模型, 使得制定的太湖分区分时水 质目标更加科学、合理. 另一方面, 由于模型输人数据存在的误差、模型结构上存在的对湖泊生态系统过程概 化的片面性, 模型参数选取存在的人为经验因素, 以及模型在时间、空间数值计算中存在的尺度问题, 致使模 型的输出存在一定的不确定性, 如何对不确定性进行量化, 进而减小决策过程的风险问题也值得深人研究.

\section{4 结论}

基于环境条件决定生态系统结构和演变以及生态系统对环境的可产生反馈作用及通过自组织适应生 态学原理, 以藻类生物量减小、沉水植物生物量增加为识别水生态系统健康状况提升的判据, 构造了水质目 标优化模型优化目标函数, 将水质目标优化模型与湖泊生态系统结构动力学模型实施耦合, 基于不同保证 
率的出人湖河道流量情景及湖泊污染物不同浓度情景下耦合模型数值试验输出的水生态系统要素时空演 化结果, 分区识别各污染物浓度情景下水生态系统健康状况, 建立氮、磷等污染物浓度与健康状态的联系, 进而确定了不同流量情景下、不同时间尺度下大型湖泊各分区总氮、总磷、氨氮、高锰酸盐指数等主要污染 物指标的控制浓度.

与传统的水质目标制定方法相比, 本文提出的太湖水质目标制定方法的优势主要体现在：(1)提出的 “动 态” 目标制定方法能够更及时地根据太湖的实时水质状况做出科学调整; (2)方法不但考虑了湖泊水体的使 用功能, 同时兼顾了湖泊生态功能, 更有利于太湖藻类水华控制与生态系统功能恢复; (3)时间上考虑了月、 季、年 3 个不同尺度,空间上考虑了贡湖等 8 个分湖区, 更加有利于太湖水环境的精细化管理.

\section{5 参考文献}

[ 1 ] Nanjing Institute of Geography and Limnology, Chinese Academy of Sciences. A summary of the water quality, water quantity and biotic resources survey for lakes of China in 2009, 2009. [中国科学院南京地理与湖泊研究所. 中国湖泊水 质、水量和生物资源调查 2009 年项目工作进展总结报告, 2009.]

[ 2 ] Schinder DW. Recent advances in the understanding and management of eutrophication. Limnology and Oceanography, 2006, 51(1, part 2): 356-363.

[ 3 ] Antoniades D, Michelutti N, Quinlan R et al. Cultural eutrophication, anoxia, and ecosystem recovery in Meretta Lake, High Arctic Canada. Limnology and Oceanography, 2011, 56(2) : 639-650.

[ 4 ] Li HP, Chen WM, Yang GS et al. Reduction of nitrogen and phosphorus emission and zoning management targeting at water quality of lake or reservoir systems: A case study of Shahe Reservoir within Tianmuhu Reservoir area. J Lake Sci, 2013, 25(6) : 785-798. DOI: 10.18307/2013.0602. [李恒鹏, 陈伟民, 杨桂山等. 基于湖库水质目标的流域氮、磷减排与 分区管理一一天目湖沙河水库为例. 湖泊科学, 2013, 25(6) : 785-798.]

[ 5 ] EC. Directive 2000/60/EC of the European Parliament and of the Council establishing a framework for community action in the field of water policy. European Community, Brussels, 2000.

[ 6 ] Gerald S, Rene F, Marina C et al. Implementation of European marine policy: New water quality targets for German Baltic waters. Marine Policy, 2015, 51: 305-321.

[ 7 ] Dowd BM, Press D, Huertos ML. Agricultural nonpoint source water pollution policy: The case of California's central coast. Agriculture, Ecosystems \& Environment, 2008, 128(3) : 151-161.

[ 8 ] Anonymous. Water Quality Improvement Plan for the Burnett Mary Region. Burnett Mary Regional Group for Natural Resource Management and Natural Decision. Bundaberg, Queensland, Australia, 2015.

[ 9 ] Hu WP, Qin BQ, Pu PM. A three-dimensional numerical simulation on the dynamics in Taihu Lake, China (I): the water level and the current during the 9711 typhoon process. J Lake Sci, 1998, 10(4) : 17-25. DOI: 10.18307/1998.0403. [胡维平, 秦伯强, 誉培民. 太湖水动力学三维数值试验研究—- 1 . 风生流和风涌增减水的三维数值模拟. 湖泊 科学, $1998,10(4): 17-25$.]

[10] Hu WP, Qin BQ, Pu PM. A three-dimensional numerical simulation on the dynamics in Taihu Lake, China (II) : the typical wind-driven current and its divergence. J Lake Sci, 1998, 10(4) : 26-34. DOI: 10.18307/1998.0404. [胡维平, 秦 伯强, 寚培民. 太湖水动力三维数值试验研究—-2. 典型风场风生流的数值计算. 湖泊科学, 1998, 10(4): 26-34.]

[11] Hu WP, Qin BQ, Pu PM. A three-dimensional numerical simulation on the dynamics in Taihu Lake, China (IV): transportation and diffusion of conservative substance. J Lake Sci, 2002, 14(4) : 310-317. DOI: 10.18307/2002.0403. [胡维 平, 秦伯强, 兴培民. 太湖水动力三维数值试验研究—4. 保守物质输移扩散. 湖泊科学, 2002, 14 (4): 310-317.]

[12] Hu WP, Jørgensen SE, Zhang FB. A vertical-compressed three-dimensional ecological model in Lake Taihu, China. Ecol Modell, 2006, 190: 367-398.

[13] Hu LM, Hu WP, Zhai SH et al. Effects on water quality following water transfer in Lake Taihu, China. Ecol Modell, 2010, 36: 471-481.

[14] Zhang HJ, Hu WP, Gu K et al. An improved ecological model and software for short-term algal bloom forecasting. Environ Model Softw, 2013, 48: 152-162.

[15] Han T, Zhang HJ, Hu WP et al. Research on self-purification capacity of Lake Taihu. Environ Sci Pollut Res, 2015,22 (11) : 8201-8215.

[16] Wang YP, Hu WP, Peng ZL et al. Predicting lake eutrophication responses to multiple scenarios of lake restoration: A three-dimensional modeling approach. Water, 2018, 10: 994. 